\title{
Exploring the Development of Undergraduate Students' Information Literacy through Their Experiences with Research Assignments
}

\section{Amanda L. Folk}

\begin{abstract}
Although information literacy has been fundamental to the work of teaching librarians for decades, the ways in which students develop their information literacy is not well understood. In addition, the sociocultural nature of information literacy is often neglected when attempting to assess students' information literacy development. The purpose of this study is to discover factors that could potentially enable or constrain the development of undergraduate students' information literacy through qualitative research that explores first-generation college students' experiences with research assignments throughout college. ${ }^{1}$
\end{abstract}

\section{Introduction}

Information literacy has received a lot of attention in the library and information science (LIS) literature since its emergence as a concept more than 30 years ago. In addition to literature that addresses how information literacy is or should (not) be defined, much of this attention has been related to how best to teach information literacy, especially given the many constraints that teaching librarians are attempting to navigate, such as the prevalence of one-shot instruction sessions. Another facet of the literature related to information literacy addresses various assessments of students' information literacy at a point in time or before and after some type of an intervention. This literature is valuable from both scholarly and practical standpoints; however, a gap in our professional knowledge remains. The ways in which students, particularly undergraduate students, develop ${ }^{2}$ their information literacy during college is not well understood. Understanding how students develop their information literacy, including factors that might enable and constrain this development, is vital for identifying appropriate teaching practices, partnerships, collaborations, and assessments.

Identifying the factors that shape the development of students' information literacy is essential, given the shift from a primarily skills-based conceptualization of information literacy as articulated in documents like the Information Literacy Competency Standards for Higher Education to the identification and articulation of ways of thinking and knowing related to information literacy in documents like The Framework for Information Literacy for Higher Education. ${ }^{3}$ Even before this formal shift materialized, several scholars had been pushing for the profession to

\footnotetext{
*Amanda L. Folk is Assistant Professor and Head, Teaching \& Learning at The Ohio State University Libraries; email: folk.68@osu.edu. (02021 Amanda L. Folk, Attribution-NonCommercial (https://creativecommons.org/ licenses/by-nc/4.0/) CC BY-NC.
} 
recognize the sociocultural and contextual nature of information literacy. ${ }^{4}$ While information literacy, to a certain extent, might be universal, there are manifestations that are situated and negotiated. For example, what constitutes information literacy in a medical environment might be different from what constitutes information literacy in a legal environment. In other words, conceptualizations of what constitutes information literacy might not transfer neatly across disciplines or professions or between different cultural contexts. ${ }^{5}$ Because of the contextual and situated nature of information literacy, social and cultural factors likely play a significant role in the development of an individual's information literacy.

In this paper, I share the findings of a qualitative research study that explores firstgeneration college students' experiences with research assignments to highlight factors that might enable or constrain the development of undergraduate students' information literacy within the postsecondary academic context. I argue that more attention must be paid to the ways in which undergraduate students develop their information literacy during college, as it is critical to students' success in college, as well as to their current and future personal, professional, and civic lives. Without an understanding of the factors that enable or constrain the development of information literacy in college, teaching librarians do not have a firm foundation for making decisions related to appropriate instructional activities, either in the classroom working directly with students or in collaborating with instructors on course and assignment design.

\section{Literature Review}

\section{The Sociocultural Nature of Learning and Literacy}

Even before the more formalized shift away from a skills-based conceptualization of information literacy occurred, many LIS scholars and scholar-practitioners argued that a consideration of the sociocultural context of information literacy is necessary. ${ }^{6}$ This argument has its roots in constructionism, or a focus on "the collective reality whereby meaning is produced and organized through 'shared understandings, practices and language'" of a culture or community. ${ }^{7}$ A constructionist perspective indicates that learning is shaped by understanding the values of the community related to information use, communication, and knowledge construction. ${ }^{8}$ Indeed, Vygotsky highlights that social interactions are critical to individual learning, stating that learning "appears twice: first on the social level and later on the individual level; first between people (interpsychology) and then inside the child (intrapsychology)."

Since its inception, the use of the word literacy in the phrase information literacy has been problematic and subject to critique. It creates a false dichotomy-someone is either literate or illiterate. Because an individual can be perceived as information illiterate, ${ }^{10}$ librarians might assume a deficit approach to working with individuals to develop their information literacy. A sociocultural approach to information literacy argues that information literacy is, in fact, situational, and individuals are developing their information literacy as they navigate and negotiate a particular context. In other words, information literacy should be viewed on a spectrum and as a process of understanding and becoming. Furthermore, literacy, in general, is situated within sociocultural contexts that are imbued with ideologies and hierarchies of power. ${ }^{11}$ This means that there are powerful individuals who determine what it means to be literate and who qualifies as literate. When we take a sociocultural approach to information literacy, we recognize the ways in which power can be wielded to either include or exclude. This can be particularly problematic in terms of information literacy in postsecondary edu- 
cation in the United States and many other Western countries, as our postsecondary institutions have largely been developed within a culture that has its historical roots within white, upper-class, patriarchal, heterosexual, cisgendered culture. For students whose backgrounds have traditionally been marginalized in higher education, information literacy likely has the power to exclude, even if that power remains invisible. ${ }^{12}$

\section{Conceptualizing the Social Nature of Information Literacy}

Both Annemaree Lloyd ${ }^{13}$ and I have used Jean Lave and Etienne Wenger's communities of practice concept ${ }^{14}$ to highlight the significance of the sociocultural aspects of information literacy and conceptualize how individuals in a particular context might develop their information literacy over time. Communities of practice describes the ways in which an individual joins a community and learns the expectations for participating in that community. ${ }^{15}$ In particular, it emphasizes the importance of social interactions for new members to learn about the community's cultural norms, including interactions with more established members as well as interactions with novice members or peers. The cultural norms of the community may be tacit, invisible, or hidden to people who are not part of the community; therefore, demonstrating an understanding of these norms is important for signaling belonging and being accepted as a legitimate member of the community. In terms of information literacy, Lloyd states that the community's cultural norms include "the sanctioning of legitimate information, the creation of knowledge and mutual understanding, and the shaping an enacting of identity."16 In addition to social interactions, Lave and Wenger highlight the role of situated learning theory in the process of becoming a member of a community. This means that new members learn about the cultural norms of the community through active participation in the community.

For the research study discussed in this article, I developed a working conceptual framework using the communities of practice concept as a heuristic to explore the development of undergraduate students' information literacy (see figure 1). I will briefly present the conceptual model in this article, but I provide a more in-depth exploration of the model in a forthcoming book chapter. ${ }^{17}$

In the working conceptual framework, first-year college students are positioned on the periphery of the undergraduate academic community of practice. The core of the undergraduate academic community is composed of privileged academic literacies, which "include particular ways of constructing meaning, making judgments, and determining what counts as valuable knowledge reflecting tacit beliefs and values." ${ }^{18}$ Information literacy is one of these privileged academic literacies that students are expected to develop as they become more established members of the undergraduate academic community. Through their coursework and the accumulation of social capital, ${ }^{19}$ students move toward the core of the community (in other words, they develop their academic literacies). Social capital refers to the accumulation of information about how to navigate or participate within a particular culture or community through interactions or relationships with others within that community. Though Lave and Wenger do not use the phrase "social capital," it is critical to becoming an established member of the community as it provides students with the information they need to successfully participate in the community based on what the community values and deems as appropriate behavior. Students likely accumulate social capital by developing relationships with their course instructors but also with other established members of the community, such as librarians, advisors, tutors, and student life 


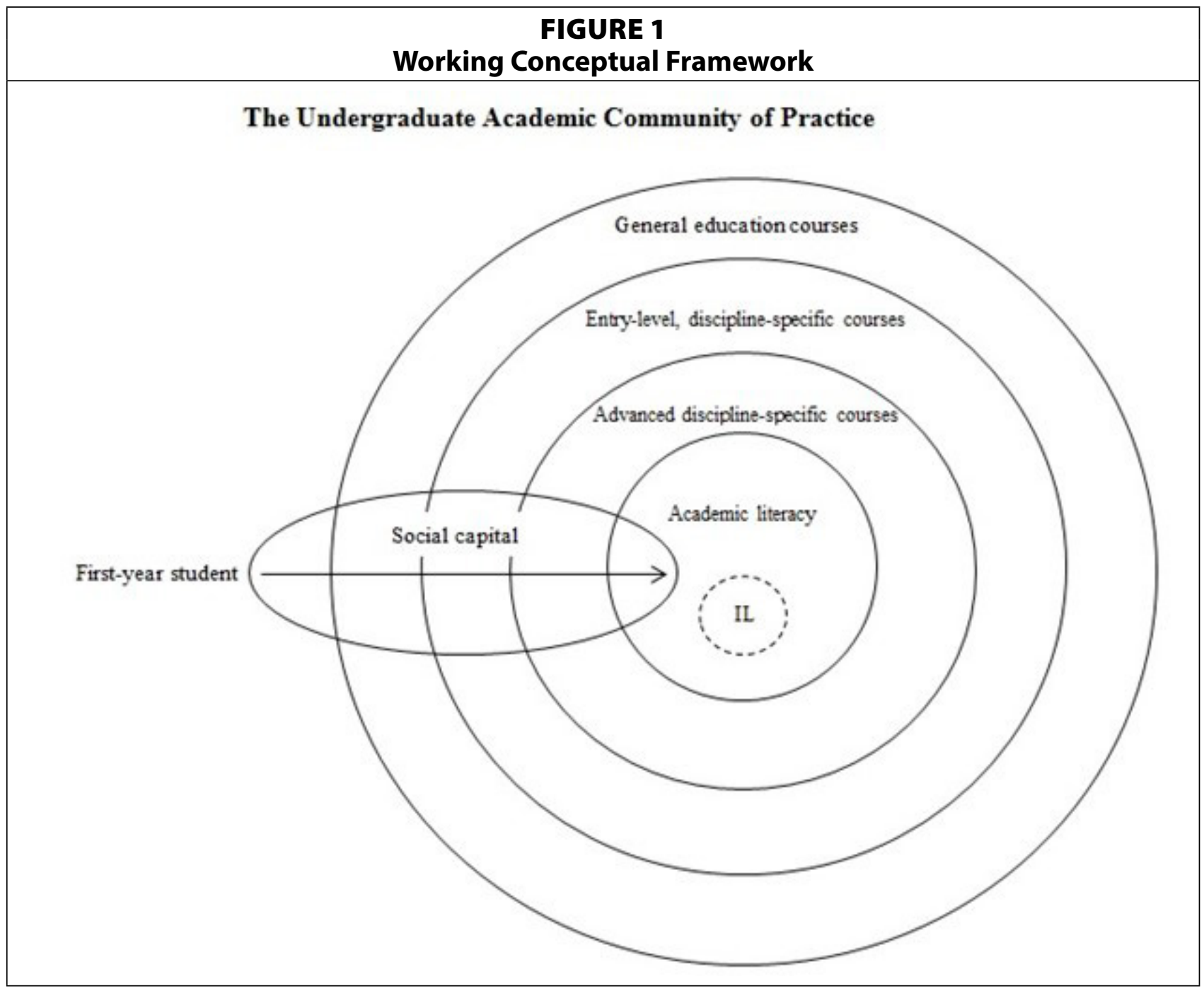

staff. Implicit in the model is the power that instructors have in setting the expectations for participation and assessing students' performance relative to those expectations. In sum, the working conceptual framework posits that both the accumulation of social capital and situated learning within the curriculum theoretically help students to develop their information literacy as they become more established members of the community (that is to say, moving from entry toward degree completion).

Before discussing a particular kind of situated learning opportunity - research assignments-I would like to point out the problematic notion of students being acculturated into the undergraduate community of practice. As mentioned earlier, higher education in the United States and other Western cultures has its historical roots in privileged cultures - white, heteronormative, upper-class, cisgendered, patriarchal cultures. In a different article, I address the problematic nature of information literacy and acculturation for students whose identities have been traditionally marginalized in higher education..$^{20}$ We need to consider how we can help students be successful in academic culture as it is right now, since success or failure has real material implications for students, while simultaneously considering how we change our culture, systems, structures, and processes to be more inclusive of and equitable for diverse student, staff, and faculty populations that comprise our institutions. 


\section{Research Assignments and Situated Learning}

In this study, I view research assignments as situated learning opportunities, in which students are expected to develop and demonstrate their evolving information literacy within the undergraduate academic community. While some students might work on their research assignments in relative isolation, these assignments have a sociocultural component, in that instructors create the expectations for performance, decide how they will communicate those expectations and how to help students meet them, and ultimately assess students' performance in meeting those expectations. James Elmborg referred to activities like research assignments as "literacy events," which require students to know "the codes used by the community and the customs and conventions in play." 21

Although research assignments are common in the undergraduate academic experience in the United States, ${ }^{22}$ little attention has been paid to the ways in which these assignments relate to or demonstrate the development of students' information literacy.$^{23}$ Instead, existing research mostly provides a snapshot of the decisions the students make in searching for, evaluating, and using information for an assignment at a single point in time. Existing scholarship has indicated that there might be an expectations gap between students and instructors with respect to these assignments. ${ }^{24}$ Gloria Leckie highlighted the difficulties and challenges that undergraduate students might face when completing these assignments, since instructors, who are expert researchers, have designed these assignments. ${ }^{25}$ What might seem relatively straightforward to an expert researcher might actually be quite complex for a novice researcher, one who might not have the topical knowledge or vocabulary to confidently negotiate searching for, evaluating, and using information in that context. As a result, Leckie believes that students end up developing a coping strategy rather than developing their information literacy. Because of this, students might fall short of meeting their instructors' expectations, and instructors might make assumptions about how much time and effort students put into the assignment. Barbara Valentine found that students did exert "legitimate effort" in completing research assignments, but they often focused on the explicit instructions related to formatting and the number of sources rather than the more abstract expectations related to critical thinking and information literacy, which can be difficult to articulate. ${ }^{26}$

While discussions of the sociocultural nature of information literacy are not new, we do not have a good understanding of how undergraduate students develop their information literacy during college. This development is a process of becoming, as students become steeped into academic and disciplinary cultures. This kind of understanding likely necessitates research studies that are both qualitative and longitudinal, both of which require significant resources (such as time, funding, and expertise) to do. However, there are research methods that allow us to do an initial exploration of this process of becoming, which could inform future in-depth, time- and resource-intensive research. In the next section, I describe a study that uses phenomenological interviewing to conduct an initial exploration of how students develop their information literacy throughout college through their experiences with research assignments.

\section{The Research Study}

This study examines first-generation college students' experiences with research assignments to explore the potential connection of this common academic experience, in which students are expected to develop and demonstrate their information literacy, to the persistent social- 
class equity gap ${ }^{27}$ in higher education in the United States. In general, first-generation college students are students whose parents have not completed a four-year college degree. Existing research indicates that first-generation students in the United States are less likely to complete their degrees than their continuing-generation peers, ${ }^{28}$ resulting in a social-class equity gap..$^{29}$ There are many factors that contribute to this equity gap, one of which is access to information about expectations for participation and performance in academic culture, which might not be transparently communicated, thus remaining tacit for many students. ${ }^{30}$ Research assignments require students to understand the discursive practices - the ways of inquiring, thinking, knowing, and communicating - that are privileged in academic culture or within a specific disciplinary culture. ${ }^{31}$ Information literacy is a critical component of those privileged discursive practices. ${ }^{32}$ Therefore, this study seeks to explore the ways in which first-generation students, who may or may not have critical information related to privileged discursive practices, determine instructors' expectations for performance on research assignments throughout college. ${ }^{33}$ By asking these students about their experiences with research assignments throughout college, I begin an initial foray into identifying how undergraduate students' information literacy develops throughout college and potential factors that could enable or constrain that development.

\section{Sample and Research Context}

The study's sample included 30 first-generation college students who were between the ages of 18 and 24 in at least their third year of study at two regional campuses of a research university in the Mid-Atlantic. Table 1 provides descriptive information about the participants' demographics. Table 2 provides basic characteristics of each campus, which I collected from each campus's website and from the Integrated Postsecondary Education Data System (IPEDS). Pseudonyms have been assigned to each campus - the Manchester campus and the Springfield campus. A salient characteristic that both campuses share is a requirement that students

\begin{tabular}{|l|l|l|l|}
\hline \multicolumn{5}{|c|}{ TABLE 1 } \\
\hline Campus & & Academic Major Division & \\
\hline Manchester campus & $12(40 \%)$ & Behavioral and Social Sciences & $7(23 \%)$ \\
\hline Springfield campus & $18(60 \%)$ & Biological and Health Sciences & $8(26 \%)$ \\
\hline & & Communication and the Arts & $5(17 \%)$ \\
\hline Sex & & Cross-divisional Double Major & $2(7 \%)$ \\
\hline Female & $20(67 \%)$ & Management and Education & $6(20 \%)$ \\
\hline Male & $10(33 \%)$ & Physical and Computational Sciences & $2(7 \%)$ \\
\hline & & & \\
\hline Race/Ethnicity^ & & Academic Level & \\
\hline Asian/Asian-American & $2(7 \%)$ & Junior & $11(37 \%)$ \\
\hline Black/African-American & $6(20 \%)$ & Senior & $18(60 \%)$ \\
\hline Hispanic/Latina/o/x & $1(3 \%)$ & Recent graduate* & $1(3 \%)$ \\
\hline Pacific Islander & $1(3 \%)$ & & \\
\hline White & $20(67 \%)$ & & \\
\hline $\begin{array}{l}\text { ^Participants were asked to self-report their race/ethnicity. } \\
\text { *Graduated 4 weeks before interview. }\end{array}$ & \\
\hline
\end{tabular}




\begin{tabular}{|l|c|c|}
\hline \multicolumn{3}{|c|}{ TABLE 2} \\
\hline & Springfield & Manchester \\
\hline Undergraduate academic programs & 26 majors, 19 minors & 40 majors, 50 minors \\
\hline Undergraduate enrollment & 1,477 full-time & 1,385 full-time \\
& 101 part-time & 114 part-time \\
\hline$\%$ of nonwhite students & $21 \%$ & $27 \%$ \\
\hline$\%$ female students & $52 \%$ & $54 \%$ \\
\hline$\%$ of students 24 year of age or younger & $92 \%$ & $89 \%$ \\
\hline$\%$ of Pell Grant recipients & $52 \%$ & $44 \%$ \\
\hline$\%$ of students retained from first to second year & $76 \%$ & $72 \%$ \\
\hline Six-year completion rate & $53 \%$ & $52 \%$ \\
\hline
\end{tabular}

complete a capstone project in their major(s) prior to graduation. Although the requirements of the capstone experience vary from discipline to discipline, these courses are designed such that students demonstrate their ability to develop and complete a scholarly research project within their major field(s) of study at the undergraduate level.

\section{Recruitment}

After the study was determined to be exempt by the Institutional Review Board (IRB), I worked with administrators at each of the two research sites to identify first-generation college students who were in at least their third year of study based on credit hours. In addition to their names, I also received their date of birth, major field(s) of study, sex, and race/ethnicity. After receiving the data, I removed students who were not of a traditional college-going age (that is, 18 to 24 years old) and students who were not enrolled full-time. In total, 278 students were identified as potential participants in the study - 156 students at the Manchester campus and 122 students at the Springfield campus. Using these lists, I emailed potential participants to explain the research study, solicit interest in participation, and inform them of the participation incentive - a \$25 gift card for a completed interview lasting no more than 75 minutes. Students who expressed interest in participating were asked to answer a brief, pre-interview questionnaire that confirmed their eligibility (in other words, first-generation status, at least 18 years of age).

\section{Data Collection}

I used a modification of Irving Seidman's phenomenological interviewing to conduct oneon-one, semistructured phenomenological interviews. ${ }^{34}$ Seidman offers a three-interview approach to phenomenological interviewing, which addresses the participants' background in light of the phenomenon being explored as well as their "present lived experience" with the phenomenon, and then asks the participants to reflect on the meaning of their experiences with the phenomenon. ${ }^{35}$ According to Seidman, the focus on describing past and present experiences helps the participants to reflect on the meaning of those experiences.

Rather than conducting three separate interviews with each participant, I used Seidman's three-interview approach to structure an open-ended, semistructured interview protocol for a single 60- to 75-minute interview with each participant. In addition to asking participants to describe their experiences in transitioning from high-school to college-level coursework, 
I asked each participant to describe their first experience completing a college-level research assignment, including what they remembered about figuring out what they were expected to do, what strategies they used to develop their topics and to find and evaluate information to use in the assignment, and what feedback they received on the assignment. Using similar questions, each participant was then asked to describe their most recent experience with a research assignment within their major field(s) of study. Participants were asked to describe their understanding of what it takes to be a successful college student; how their confidence in completing academic research assignments had changed, if at all; how their strategies for figuring out what the expectations for performance had changed; and what role they believe academic research assignments played in their undergraduate education. I received permission from each participant to record the interview on my laptop, which was then transcribed by a professional transcription service.

\section{Data Analysis}

I used two methods to analyze the data that I collected: writing memos and coding. First, after the interviews were complete, I used the audio recordings to construct an experiential $\mathrm{memo}^{36}$ for each of the students. The purpose of these experiential memos was to transform the interview data into a coherent narrative describing each of the participants' reflections on their experiences. These memos helped me to be open to the participants' lived experiences and aided in the process of identifying themes that cut across multiple interviews that could be used for the first phase of coding. Each participant was asked to review the experiential memo for their individual interview and invited to comment on my understanding of their experience. In addition to providing verification that I did not misunderstand or misinterpret their experiences, this was also an opportunity to provide more detail about their experiences, if necessary. Eight participants (27\%) responded to my email invitation to provide feedback, each affirming that the experiential memo I had constructed was representative of their experience.

As I constructed the experiential memos, I began to record themes that were emerging to be used for an initial round of coding. In total, I identified 18 codes, including themes related to the study's research questions and conceptual framework and themes that emerged from the interviews, for the initial round of coding. Using Microsoft Word and Excel, I read through each interview transcript and applied these preliminary codes to the transcripts and copying and pasting portions of the transcripts into an Excel spreadsheet. After coding each transcript, I returned to the Excel spreadsheet and read the passages for each of the 18 codes. At this point, I identified salient themes to create a more detailed coding schema for a second round of analysis. At this point, I identified 171 codes. I used Dedoose, a web-based qualitative analysis application, to facilitate the second round of coding.

To facilitate the second round of coding, I grouped the transcripts into six groupsBlack/African-American students, other students of color, white male students, white female Manchester students, and white female Springfield students. The purpose of these groupings was to identify potential themes within and across various demographic groups, as well as to provide built-in milestones for reflection and journaling after coding approximately five to seven transcripts. During the second round of coding, I wrote thematic memos. ${ }^{37}$ When I completed the second round of coding for each group identified above, I wrote memos for that group of students based on the study's research questions. After writing these thematic 
memos, I began to map the relationship(s) between the emergent themes and connected these themes to the study's conceptual framework.

\section{Limitations}

Although this study did not seek to recruit a sample that was representative of the entire firstgeneration student population, the demographics of the Manchester and Springfield campuses present a limitation. Nationally, first-generation students tend to be more diverse in terms of race/ethnicity; however, the Manchester and Springfield student bodies are predominantly white (73\% and 79\%, respectively). Despite this, the sampling strategy I employed resulted in overrepresentation for students of color. Students of color made up 24 percent of the eligible participant pool. Of the participants in the study, 33 percent identified as students of color, which is aligned with national trends.

Although phenomenological interviewing is a strength of this study, in that it allows for a longitudinal glimpse into students' information literacy development, students' memory is a limitation of this data collection method. In some interviews, a student may have been discussing a research assignment that happened two to three years prior. In addition, the emotions that students felt or the meaning that they made of an experience will change over time, as they have new experiences. They will remember and interpret past experiences through a different lens than they did at the time.

My former professional role at one of the two campuses included in this study might also present a limitation. I was a librarian at one of the two campuses for six years, including during the data collection phase for this study, and helped many students with their research assignments through formal or informal teaching activities. While my teaching role diminished over those six years, the participants located at that campus may have worked with me as first- and second-year students. This means that they might have chosen to participate in the study based on previous interactions with me or they may not have felt they could be entirely honest during the interview (in other words, the assumption that there is a correct way to answer the questions).

\section{Findings}

Data analysis revealed four themes related to factors that may enable or constrain students' development of their information literacy during their undergraduate academic experience through research assignments: 1) their experience transitioning from high school to college; 2) the perceived role(s) of research assignments in college; 3) perceived emphasis of product over process; and 4) their motivation to learn. These findings are intended to serve as indicators of how students navigated the process of identifying and meeting their instructors' expectations for performance on research assignments in college. In other words, these findings highlight the ways in which these students perceived that they learned to become successful members of the undergraduate academic community with an explicit focus on the development of information literacy.

\section{Transitioning from High School to College}

The students in this study exhibited two different approaches to their academic transition from high school to college: a social approach and an individual approach. The approach that a student exhibited seemed to be related to how successfully they were able to transfer and 
apply the academic skills and strategies that they developed in high school to their new collegiate environment. The approach that students exhibited seemed to affect the accumulation of social capital within their new academic environment.

Students who took a social approach initiated interactions with their instructors early in their collegiate careers, even if they did not feel entirely comfortable doing so, because they knew it would be important to their learning and success. When they recognized that their collegiate academic work seemed different from what they had done in high school, they seemed to understand that speaking with their instructor would help them to understand their new context. Not only were these interactions a way to fill gaps in knowledge or skills, some students saw this as an opportunity to establish a reputation as a "good student." Alexis shared, "If I didn't understand something, I would just go ask. Obviously, professors like their students that actually cared about their grades. That's what helped me establish a little bit of myself."

Other students exhibited an individual approach to this transition - they either did not know they could and should reach out to their instructors to support their learning and performance or they were too intimidated to do so. These students seemed to implicitly believe that the burden of determining and meeting instructors' expectations was solely on their shoulders. In some cases, high school teachers had scared some of these students, speaking in a threatening way about what college instructors would or would not tolerate. In other cases, they were intimidated by the educational and/or professional attainment of the instructors.

Students who took an individual approach often struggled with their research assignments in their first couple of years of college, because the expectations seemed different from high school and they had not yet developed support networks to help them to understand the expectations of their new educational context. Despite being diligent students, some of these students reported failing assignments or courses due to their performance on research assignments. For example, Emily applied the skills and strategies she had successfully used to complete high school research assignments when she first arrived at college. She felt that the paper was the best paper she had ever written and was "proud" of herself, so she was "heartbroken" to learn that she had plagiarized. She reflected, "It's just it was new and hard, and apparently, I didn't know what I was doing...I think it was just in high school, we were taught if you want to take a sentence exactly, you just use the quotations and cite it behind it. Well, they didn't want that. They want you to put it in your own words, but you still have to cite it."

However, students who took an individual approach seemed to benefit from required interactions with their instructors or with other learning support staff (such as writing tutors or librarians) as they were working on assignments. These required interactions conveyed the sentiment that instructors and staff were invested in students' success and wanted to support students in their courses. In addition, entry into a student's major field(s) of study helped the student to get to know their instructors over time. Both campuses were small, so students typically had the same instructor for multiple courses and they began to feel more comfortable approaching these instructors as they developed a relationship with them.

Although a shift to a social approach was evident in most students' reflections as they settled into their college major and got to know their instructors, there were positive longerterm implications for students who took a social approach to the high school-to-college transition. These students were more likely to leverage the social capital they had accumulated 
into opportunities for mentoring and higher levels of achievement, including working on a faculty member's research project, presenting at conferences, or being explicitly groomed for graduate school. These kinds of opportunities have the potential to help students develop more sophisticated information literacy and critical thinking skills that could be applied to their future academic or professional lives.

\section{Role of Research Assignments}

When asked about the purpose of research assignments in college and why instructors gave students these assignments, many students perceived that these assignments were situated learning experiences, though they didn't use that phrase. The students described several purposes of research assignments in college, including the assessment of learning, the opportunity to learn more about topics related to the course, the demonstration of critical thinking skills, opportunities to challenge students, and preparation for postcollege life.

In general, students believed that research assignments in lower-level courses were meant to prepare them for future research assignments, including their capstone experiences. Alexis alluded to this process of becoming, sharing, "I think the smaller ones are to lead us up to what's expected of us our upperclassmen years. Trying to get as meshed into the college world, coming from high school. Doing it a little but more gradually than just throwing a big, huge project at us." Gabrielle shared a similar sentiment, reflecting, "All throughout my three and a half years, four years being here, it's all been research and papers - I was like, no wonder why they started me off in [basic composition] because it's a lot that you need to know, especially with these research papers." Just as students reported that many of their professors broke larger research assignments into smaller assignments to help them progress toward completing the larger assignment in a course, many students perceived similar scaffolding within the curriculum.

Students indicated that capstone projects were intended to demonstrate that students learned what they were supposed to learn throughout their collegiate experience, validating them as more established members of the community. Cheyenne shared, "I guess that's what they want to see, if we learned what they taught us, if we were paying attention to what they were teaching. Yeah, the capstone's really throwing everything that I've learned from all the [professors in my major] into one thing." Gabrielle elaborated on the validation of membership in the community, stating, "What have you learned all the way up to now that you can take from this?...Providing that you passed it, you're ready. You've done your job here, pretty much. You've learned everything that you needed to know." These perceptions of the purpose of the capstone experience indicate that students are aware that learning is scaffolded and cumulative, and they are expected to demonstrate how much they have learned since throughout college. In other words, successful performance on the capstone project was indicative of successful participation in the community.

\section{Product over Process}

Students perceived that final products, such as papers or presentations, were valued more than the processes they used to develop the products. In general, students reported being taught a checklist approach to evaluating and using sources in high school, and for many students the perception of product-over-process reinforced that approach. Most students reported being taught the same basic set of evaluation criteria in high school, and they relied on these criteria in college. These criteria include looking at a website's domain (like .org, .gov, .edu), 
avoiding Wikipedia, looking at the author and publication date, and fact-checking a source by looking at other sources. The ways in which students described applying these criteria suggested that they approached information evaluation as a process of checking off boxes on a list rather than as a process that included critical thinking.

However, many students noted that the stakes felt higher in college and realized that some of the items on their checklist needed to change in their new environment. Frequently, this resulted in peer-reviewed or scholarly articles being added to the checklist. Dustin succinctly made this comparison - "High school, it was credible. [The sources we used] were real, not fake ones, but never official scholarly stuff." Kayla elaborated a bit more on this change, sharing, "In high school you just Googled and found some [sources]. I knew definitely not to use Wikipedia or something like that, but I mean sometimes you'd grab a book. I mean you would just look it up and if it looks like a legitimate source then it was okay. College and I think definitely because of just the audience that we were writing for and how not necessarily serious, but I mean it's not a joke anymore. It's college. It's a real research paper."

Even though many students shared that the stakes felt higher in college and that they recognized a commensurate difference in their instructors' expectations, this often did not seem to result in deep or critical engagement with their sources. Part of this was based on the feedback they received from their instructors on their work, which seemed to reinforce that the students could be successful without this kind of deep and critical engagement. In other words, they did not perceive that the development of more sophisticated modes of thinking related to information-seeking and use was important to participate successfully in the undergraduate academic community. Many students perceived the emphasis to be on their writing skills, including both grammar and style. Brooke reflected, "I think mostly it was grammar and spelling, and then I know she focused a lot on using different types of sentence structure. She would try to get us to change our sentences so we weren't using all the same. I don't think [sources] was really a big thing." When students did receive feedback on their sources, particularly written feedback, they reported it was mostly related to correcting errors in their citations, not necessarily about the ways in which the students engaged with and used the contents of those sources.

\section{Motivation to Learn}

Students' motivation to learn more about a particular topic, especially if it was salient to their identities, seemed to result in deeper engagement with sources and the demonstration of the dispositions and knowledge practices related to information literacy. Two different orientations to research assignments emerged from the interviews-a performance orientation and a learning orientation-the latter of which seems to be critical for the development of information literacy. ${ }^{38}$ In a performance orientation, students expressed an interest in doing well on the assignment. They typically picked a topic that was of interest to them as a way to motivate themselves to complete the assignment and lower the barrier to success. Students who exhibited a learning orientation not only wanted to do well on the assignment, they also expressed a genuine desire to learn or to help others learn as a result of the research that they were doing. Students whose identities were minoritized beyond their first-generation status seemed more likely to exhibit a learning orientation. ${ }^{39}$ Of the students who participated in the study, only students who demonstrated a learning orientation exhibited some of the dispositions and knowledge practices related to informa- 
tion literacy. In this section, I provide three examples of a learning orientation and how it relates to information literacy.

A few of these students shared an awareness of existing discourse about their topics in nonscholarly communities of which they were a part. For example, Malik, a Black male, identified the discourse about gentrification in Black popular culture, pointing to its presence in the popular film Boyz $n$ the Hood. He shared, "There was a scene in that movie where Furious Styles explains to everyone in Compton, California, the effects of gentrification and how it was affecting their area in Long Beach or Compton or wherever they live. He was explaining to them how the property value would increase as they moved more of the Black people out by putting a gun store and a liquor store on each corner of the neighborhood and have the blacks kill themselves or make themselves even poorer just so that they can get moved out of the area and then watch their home value increase." Here Malik demonstrated an interest in combining his lived experience with gentrification and the discourse found in Black popular culture to educate his peers at the predominantly white Manchester campus about this issue. Students who were motivated to learn about their topics demonstrated an awareness that their research was not happening in a vacuum. They identified relevant and specific sources of the discourse, particularly in the media or in popular culture, and exhibited a desire to engage with the discourse through their research assignments.

Other students who articulated a motivation to learn approached research as a form of inquiry and sought multiple perspectives on their topics. Gabrielle, a Black female, for example, makes gathering multiple perspectives on her topic a priority in her capstone project related to racism. Gabrielle explained, "I was just like, maybe I should just go around and ask people, not a big group like that, but actually ask questions and then see what they know, and then see if they know stuff that they can give back to me... I wanted to make sure that I had an equal amount of color in the room. I wanted people that was Puerto Rican. I wanted people that was White. I wanted people that was Black. I wanted people that was Asian, because I wanted to see exactly how they interacted and how they felt about answering those questions." Gabrielle implied that speaking generally to other people about racism was not enough to develop her own understanding of the topic; rather, it was critical for her own learning to engage students of varying races and ethnicities who may share multiple and differing perspectives on this topic.

Finally, some of these students indicated that they considered the contextual nature of authority when evaluating and selecting information sources to use in their research assignments. Despite scholarly or peer-reviewed journal articles being the gold standard for sources in college, these students did not rely solely on that category of information sources to determine whose voices needed to be incorporated into their research and moved beyond a checklist approach to gathering appropriate information sources. For example, Jasmine, a Black female, conducted interviews with people who were witnessing the school-to-prison pipeline in her hometown first-hand to get a more complete picture of her topic. She shared, “[A news article] was also factual.... It was just telling you what happened and what's going on, but...I wasn't trying to get a biased opinion from other people [that is, the news sources]." Jasmine recognized that news sources typically convey factual information, but that factual information may only present one side of the story. However, she recognized the authority and credibility of first-hand witnesses with varying experiences of and perspectives on the school-to-prison pipeline in her hometown. 


\section{Discussion}

The belief that information literacy is situated within sociocultural contexts was foundational to this research study. Although some ways of thinking, knowing, and communicating may be transferred between contexts, what constitutes acceptable information use and knowledge creation is defined within particular contexts. The purpose of this research study was to learn more about first-generation college students' experiences with research assignments in college as an initial exploration into the ways in which they learn how to successfully meet their instructors' expectations for performance on these assignments, as well as attempting to understand the ways in which their information literacy developed during college. In this article, I seek to identify some factors that might either enable or constrain students' development of information literacy in college to inform our teaching and learning work with students and instructors, paying attention to the sociocultural nature of information literacy.

The findings indicate several factors that could enable students' development of information literacy during their collegiate experience. First, and perhaps not surprising, is students' high school academic experiences, including how well those experiences prepared them for college in general but also for research assignments more specifically. In this study, this transferability between high school and college also seemed to be related to the ways in which these students began to build social capital, which provided them with important information related to instructors' expectations for performance, in their new context.

While the transferability between high school and collegiate academic experiences can serve as enabler to the continued development of students' information literacy during college, it can also serve as a constraint. In addition, it could have implications for the intersections of equity, social justice, and information literacy. Primary and secondary public-school attendance in the United States is largely based on where a student lives, and residential segregation (by both race/ethnicity and socioeconomic status) is prevalent across the United States. Based on funding structures for public schools, which heavily rely on residential taxes, school districts that serve primarily students of color and lower-income students are often underfunded and underresourced. If these students are not receiving the same quality of education that their peers in more affluent neighborhoods are, this has implications for existing and persistent equity gaps in higher education. In other words, first-year students are not entering college on a level playing field, even when their abilities and capacity for success are similar, and the findings of this study suggest that this might extend to their information literacy.

Furthermore, this constraint might also be exacerbated by intimidation that many of the students whose high school experiences did not seem to prepare them for college-level research assignments reported feeling when interacting with their instructors. Although it was not mentioned specifically by the students in this study, it is likely that some of these students did not perceive that their instructors had identities that were similar to their own based on perceptions of race or socioeconomic status. However, these students generally responded positively when their instructors proactively engaged them or encouraged or required them to meet with other learning support staff like librarians or tutors, with whom the students began to develop supportive relationships.

Finally, there might be negative implications for students who took an individual approach to the transition to college in terms of their sense of belonging or academic identities. These students often reported struggling with research assignments, and they did not feel they had the information they needed to be successful. Consistently struggling with research 
assignments due to a lack of information about expectations could lead students to question their capabilities and their ability to be successful in college, which affects the motivation and effort students will put into their coursework and their learning. ${ }^{40}$ Even if these students persist, they might be less likely to put significant effort into their assignments, thus resulting in a missed opportunity to develop or refine their information literacy.

Another factor that seemed to serve as a significant enabler to the development of students' information literacy was the meaningfulness or personal significance of the assignment topic to the student. This potential enabler also seemed to help some students overcome product-overprocess mentalities and overreliance on checklists that seem to serve as potential constraints to the development of students' information literacy within the collegiate context. Findings from The Meaningful Writing Project suggest that, when students found meaning or significance in their academic work, including assignments like research assignments, they perceived that they were able to more fully engage with course-related content and that these assignments helped them to transfer their learning to other courses or contexts. ${ }^{41}$ The students in that study indicated that this was due to the personal connections they felt to their academic work, the relevance they perceived to their academic, personal, or professional lives, and the ability to fully immerse themselves in writing and research.

Another potential enabler was the students' recognition of the expectation to develop more sophisticated research processes as they moved throughout the curriculum. In theory, these students seemed to know that they were expected to become better and more sophisticated researchers throughout college. This is positive, because this suggests they do not fully believe that the ways of thinking and knowing related to information use are completely static, as previous research has suggested. ${ }^{42}$ However, the feedback (or lack of feedback) that many students received from their instructors provides a potential counterbalance to this. Many instructors likely intend to develop students' information literacy and critical thinking, but some of their practices or behaviors might be antithetical to that goal, including the feedback that they give and the ways in which they grade research assignments. In practice, students did not perceive that it was important for them to continually develop these skills to be successful in college and that their instructors valued the final products the students were submitting more than the process used to develop those products.

In terms of the working conceptual model, these findings provide some insight into how students begin to navigate the undergraduate academic context, including the ways in which they develop strategies for gaining information about performance expectations about research assignments and the ways in which students interpret messages from instructors about the cultural values of this community. Students demonstrated two approaches to building social capital, particularly with their instructors. Not only did a student's approach seem to affect opportunities for higher levels of achievement (such as working on an instructor's research or presenting at a conference), it could have implications for students' self-efficacy related to information literacy and research assignments, since students who took an individual approach struggled through research assignments in the first couple years of college.

These findings also provide some evidence for how students might interpret messaging about values of the community related to information literacy and research assignments. On a positive note, students did seem to recognize the scaffolding within the curriculum, particularly related to research assignments, and the belief that students will continue to develop 
their information literacy, critical thinking, and research skills throughout their collegiate careers. In other words, students perceived that they were not expected to be fully established members of this new community upon entry; rather, instructors intended to help them learn and grow through participation. On the other hand, many believed that instructors value the final product over process, which conflicts with the previous value. Though many instructors might be aware that students are placing more time and effort on the final product than the research process, they might be surprised about the ways in which students believed instructors are reinforcing this belief. In addition to thinking carefully about the feedback instructors give, the findings suggest that creating learning environments that motivates students-allowing students to identify topics or issues that are personally or academically meaningful to them-might be a strategy to help overcome messaging that emphasizes product over process and enable active engagement and/or participation within the academic community.

\section{Recommendations for Practice}

The following recommendations for practice are rooted in Michelle Holschuh Simmons' conceptualization of librarians as discourse mediators. ${ }^{43}$ Academic librarians hold a "unique position that allows mediation between the non-academic discourse of entering undergraduates and the specialized discourse of disciplinary faculty" due to being "simultaneously insiders and outsiders of the classroom and of the academic disciplines in which [we] specialize." ${ }^{\prime 4}$ When the concept of discourse mediation is combined with an acknowledgment of the sociocultural nature of information literacy, it creates exciting opportunities for us to partner with students and instructors to facilitate the teaching and learning processes. Some of these recommendations might seem problematic, considering the issues of acculturation that I brought up earlier. I have addressed some of these issues in a different publication ${ }^{45}$ and encourage us, individually and collectively, to carefully consider how we can make expectations for performance in academic culture more inclusive and equitable.

First, librarians should consider partnering with instructors of key gateway courses, either in the general education curriculum or majors, to pilot required individual consultations with students that help them to recognize what they already know and can do that will transfer to their new collegiate context and to decode or identify explicitly their instructors' expectations. I recognize both that many librarians might already be doing this and that there are some clear scalability and sustainability issues with this kind of recommendation. However, I urge some consideration of how resources might need to be allocated differently to accommodate this, because the findings indicate that the development of relationships with learning support faculty and staff have positive implications for students' ability to learn the expectations related to college-level research assignments; and the students who might benefit from these interactions the most might be the least likely to initiate them. This might require a reduction in more traditional one-shot instruction sessions or a reallocation of funding and staff time to hire and rigorously train peer coaches, who are often used in writing and tutoring centers. Even if this recommendation is not ultimately achievable, I believe the consideration of it could create new approaches to partnering with students and instructors in the learning process, one that could go beyond one-shot instruction sessions and voluntary, student-initiated consultations.

My second recommendation is to consider developing and implementing instructor development programming, ${ }^{46}$ which makes visible the expertise that librarians have related to 
student learning and the development of their information literacy. ${ }^{47}$ In a recent publication, ${ }^{48}$ I urged librarians to consider working with instructors to use approaches like Decoding the Disciplines ${ }^{49}$ and Transparency in Learning and Teaching (TILT Higher Ed) ${ }^{50}$ to help develop students' information literacy in more intentional and equitable ways. The benefits of these approaches are that they can help instructors not only to more explicitly articulate expectations that are difficult to communicate (that is to say, somewhat abstract ways of thinking and knowing), but they could also result in better feedback that helps to fight against the product-over-process mentality. Another possibility is focusing on the benefits of asset-based or strengths-based approaches that enable students' motivation to learn and help them to recognize the transferability of the information literacy they have developed in other contexts to collegiate academic culture. ${ }^{51}$ Allowing students to leverage their strengths had clear positive implications for the development and demonstration of students' information literacy in this study. In addition, instructor development programming that makes visible our expertise in areas like digital humanities, geospatial data and tools, open educational practices, and publishing and articulates how this expertise could aid in the development of engaging and authentic learning experiences should be considered. Finally, instructor development programming is also an opportunity to partner with other units at our institutions that have similar goals, such as writing centers or writing across the curriculum/disciplines programs.

Finally, we should consider sustainable and scalable ways to work with school librarians and $\mathrm{K}-12$ faculty in our areas, especially for those at institutions that receive a good portion of students from public school districts in the surrounding region. Because both academic and school libraries are in positions of attempting to do more with fewer resources, this kind of partnership needs to be at the programmatic level rather than ad hoc or individual partnerships. Examples of potential partnerships would be joint professional development, in which academic librarians discuss the information literacy expectations students will face in college, and school librarians can share how information literacy is approached in K-12 classrooms. There could also be collaborative syllabi reviews to see where there may be significant curricular or learning outcomes gaps between eleventh or twelfth grade and the first year in college, especially as it relates to expectations for research assignments. Academic and school librarians could work jointly with instructors to design classes in a way that provides students with a smoother transition.

\section{Recommendations for Further Research}

Further research about how undergraduate students develop and demonstrate their information literacy within collegiate academic culture is necessary to truly understand the ways in which librarians and instructors can effectively help students to develop these ways of thinking and knowing and transfer them among different contexts. This kind of research can also provide valuable information about the ways in which current academic practices at our institutions might be transformed to become more inclusive and equitable. More qualitative research, including the use of interviews and artifact analysis, into students' experiences with research assignments is necessary. Both cross-sectional and longitudinal studies would be valuable to identify if and how students develop their information literacy at different points within their undergraduate academic careers and what enables or constrains that development over time. This research needs to be inclusive in terms of its participant samples, so that we can understand a diverse range of experiences rather than making assumptions about all 
students' experiences based on those of privileged groups of students. We also need to be careful not to establish normative experiences and use research to "fix" students who might be at the margins in terms of their identities or their experiences. Rather, this should be an opportunity to interrogate, critique, and transform cultural practices that are no longer inclusive. This research should be complemented with research that investigates different methods or approaches to developing students' information literacy, above and beyond an analysis of one-shot sessions, to identify teaching practices that are both effective in developing students' information literacy and inclusive of our diverse student populations.

\section{Acknowledgments}

The author would like to thank the reviewers for their thoughtful feedback. This manuscript is much stronger as a result.

\section{Notes}

1. This article draws upon a research study I conducted to complete the requirements of a doctoral program at the University of Pittsburgh. Some of the content that appears in "The Research Study" and "Findings" sections in this article manuscript also appears, word for word, in an unpublished doctoral thesis, which can be located here: http://d-scholarship.pitt.edu/id/eprint/35132.

2. The phrase "develop their information literacy" has two related yet distinct facets for me: Students are simultaneously expanding and refining their information literacy in 1) a general sense (that is to say, critical thinking as it relates to information evaluation and use in their personal, professional, and civic lives); as well as in 2) a specific sense (in other words, gaining knowledge about appropriate information evaluation and use behaviors within an academic and/or disciplinary context). This is based on previous scholarship from Annemaree Lloyd, in which she states, "becoming information literate is a holistic process influenced by social, physical and textual relationships with information, that requires a range of information practices and acknowledges the complexity and diversity of information sources within a landscape. By developing the textual, physical and affective skills necessary to navigate the sources within the landscape, we come to know and develop 'know how.' This relationship with information is the essence that lies at the heart of becoming an expert or having expertise in a particular context, or, to put it another way, of being information literate." See Annemaree Lloyd, "Information Literacy Landscapes: An Emerging Picture," Journal of Documentation 62, no. 5 (2006), 570-83.

3. Association of College \& Research Libraries (ACRL), Information Literacy Competency Standards for Higher Education, available online at https://alair.ala.org/handle/11213/7668; ACRL, Framework for Information Literacy for Higher Education, available online at https://www.ala.org/acrl/standards/ilframework.

4. Christine Susan Bruce, Informed Learning (Chicago, IL: ACRL, 2008); James Elmborg, "Critical Information Literacy: Implications for Instructional Practice," Journal of Academic Librarianship 32, no. 2 (2006): 192-99; James Elmborg, "Libraries in the Contact Zone: On the Creation of Educational Space," Reference \& User Services Quarterly 46, no. 1 (2006b): 56-64; Annemaree Lloyd, Information Literacy Landscapes: Information Literacy in Education, Workplace and Everyday Contexts (Oxford, UK: Chandos Publishing, 2010); Mandy Lupton, "Evidence, Argument and Social Responsibility: First-Year Students' Experiences of Information Literacy when Researching an Essay," Higher Education Research \& Development 27, no. 4 (2008): 399-414; Karen Nicholson, "Information Literacy as a Situated Practice in the Neoliberal University," Proceedings of the Annual Conference of the Canadian Association for Information Science (2014), available online at www.cais-acsi.ca/ojs/index.php/cais/article/view/901; Kimmo Tuominen, Reijo Savolainen, and Sanna Talja, "Information Literacy as a Sociotechnical Practice," Library Quarterly 75, no. 3 (2005): 329-45; Li Wang, "Sociocultural Learning Theories and Information Teaching Activities in Higher Education," Reference \& User Services Quarterly 47, no. 2 (2007): 149-58.

5. Christine Bruce and Hilary Hughes, "Informed Learning: A Pedagogical Construct Attending Simultaneously to Information Use and Learning," Library E Information Science Research, 32, no. 4 (2010): A2-A8; Annemaree Lloyd and Kirsty Williamson, "Towards an Understanding of Information Literacy in Context: Implications for Research," Journal of Library and Information Science 40, no. 1 (2008): 3-12; Mandy Lupton and Christine Bruce, "Window on Information Literacy Worlds: Generic, Situated and Transformative Perspectives," in Practising Information Literacy: Bringing Theories of Learning, Practice, and Information Literacy Together, eds. Annemaree Lloyd and Sanna Talja (Wagga Wagga, NSW: Centre for Information Studies, 2010), 3-27.

6. Bruce, Informed Learning; Elmborg, "Critical Information Literacy"; Elmborg, "Libraries in the Contact 
Zone"; Lloyd, Information Literacy Landscapes; Lupton, "Evidence, Argument and Social Responsibility"; Nicholson, "Information Literacy as a Situated Practice in the Neoliberal University"; Tuominen, Savolainen, and Talja, "Information Literacy as a Sociotechnical Practice"; Wang, "Sociocultural Learning Theories and Information Teaching Activities in Higher Education."

7. Lloyd, Information Literacy Landscapes, 9.

8 Lloyd, Information Literacy Landscapes.

9. Lev Vygotsky, Mind in Society: The Development of Higher Psychological Processes (Cambridge, MA: Harvard University Press, 1978), as cited in Wang, "Sociocultural Learning Theories and Information Teaching Activities in Higher Education," 151.

10. William Miller, "The Future of Bibliographic Instruction and Information Literacy for the Academic Librarian," in The Evolving Educational Mission of the Library, eds. Betsy Baker and Mary Ellen Litzinger (Chicago, IL: Bibliographic Instruction Section, ACRL, ALA, 1992); Stanley Wilder, "Information Literacy Makes All the Wrong Assumptions," Chronicle of Higher Education 51, no. 18 (2005): B13.

11. Rolf Norgaard, "Writing Information Literacy: Contributions to a Concept," Reference \& User Services Quarterly 43, no. 2 (2003): 124-30.

12. Amanda L. Folk, "Reframing Information Literacy as Academic Cultural Capital: A Critical and EquityBased Foundation for Practice, Assessment, and Scholarship," College \& Research Libraries 80, no. 5 (2019): 658-73.

13. Lloyd, Information Literacy Landscapes.

14. Jean Lave and Etienne Wenger, Situated Learning: Legitimate Peripheral Participation (Cambridge, UK: Cambridge University Press, 1991). Lave and Wenger's original conceptualization of communities of practice is different from the typical use of this concept in contemporary librarianship (that is to say, as a community of learners focusing on a particular topic or skills).

15. Amanda L. Folk, "Conceptualizing the Sociocultural Nature of the Development of Information Literacy in Undergraduate Education," in The Social Future of Academic Libraries: New Perspectives on Communities, Networks, and Engagement, eds. Tim Schlak, Sheila Corrall, and Paul Bracke (London, UK: Facet Publishing, forthcoming); Amanda L. Folk, "Learning the Rules of Engagement: Exploring First-Generation Students' Academic Experiences through Academic Research Assignments" (PhD diss., University of Pittsburgh, 2018), http://d-scholarship. pitt.edu/id/eprint/35132; Lloyd, Information Literacy Landscapes.

16. Lloyd, Information Literacy Landscapes, 20.

17. Folk, "Conceptualizing the Sociocultural Nature of the Development of Information Literacy in Undergraduate Education."

18. Jane Tapp, "Framing the Curriculum for Participation: A Bernsteinian Perspective on Academic Literacies," Teaching in Higher Education 20, no. 7 (2015): 711-22.

19. Pierre Bourdieu, "The Forms of Capital," in Handbook of Theory and Research for the Sociology of Education, ed. John G. Richardson (New York, NY: Greenwood Press, 1986).

20. Folk, "Reframing Information Literacy as Academic Cultural Capital."

21. Elmborg, "Critical Information Literacy," 195.

22. Alison J. Head and Michael B. Eisenberg, Lessons Learned: How College Students Seek Information

in the Digital Age (Seattle, WA: Project Information Literacy, University of Washington, Information School, 2009), retrieved from http://projectinfolit.org/publications/.

23. Alison Hicks and Adrian Howkins, "Tipping the Iceberg: A Collaborative Librarian-Historian Approach to Redesigning the Undergraduate Research Assignment," History Teacher 48, no. 2 (2015): 339-70.

24. Barbara Valentine, "The Legitimate Effort in Research Papers: Student Commitment Versus Faculty Expectations," Journal of Academic Librarianship 27, no. 2 (2001): 107-15.

25. Gloria J. Leckie, "Desperately Seeking Citations: Uncovering Faculty Assumptions about the Undergraduate Research Process," Journal of Academic Librarianship 22, no. 3 (1996): 201-08.

26. Valentine, "The Legitimate Effort in Research Papers."

27. Nicole M. Stephens, MarYam G. Hamedani, and Mesmin Destin, "Closing the Social-Class Achievement Gap: A Difference-Education Intervention Improves First-Generation Students' Academic Performance and All Students' College Transition," Psychological Science 25, no. 4 (2014): 943-53.

28. Emily Forest Cataldi, Christopher T. Bennett, and Xianglei Chen, First-Generation Students: College Access, Persistence, and Postbachelor's Outcomes (Washington, DC: US Department of Education, National Center for Education Statistics, 2018), https://nces.ed.gov/pubs2018/2018421.pdf; Jennifer Engle and Vincent Tinto, Moving beyond Access: College Success for Low-Income, First-Generation Students (Washington, DC: The Pell Institute for the Study of Opportunity in Higher Education, 2008), https:/files.eric.ed.gov/fulltext/ED504448.pdf; Terry T. Ishitani, "Studying Attrition and Degree Completion Behavior among First-Generation College Students in the United States," Journal of Higher Education 77, no. 5 (2006): 861-85. 
29. Stephens, Hamedani, and Destin, "Closing the Social-Class Achievement Gap."

30. Peter J. Collier and David L Morgan, "'Is That Paper Really Due Today?': Differences in First-Generation and Traditional College Students' Understandings of Faculty Expectations," Higher Education 55, no. 4 (2008): 425-46.

31. Elmborg, "Critical Information Literacy"; Nicholson, "Information Literacy as a Situated Practice in the Neoliberal University."

32. Folk, "Reframing Information Literacy as Academic Cultural Capital."

33. For other publications that focus on the intersection of first-generation students, information literacy, and the LIS literature, see Amanda L. Folk, "Drawing on Students' Funds of Knowledge: Using Identity and Lived Experience to Join the Conversation in Research Assignments," Journal of Information Literacy 12, no. 2 (2018): 44-59; Darren Ilett, "A Critical Review of LIS Literature on First-Generation Students," portal: Libraries and the Academy 19, no 1. (2019): 177-96; Darren Ilett, "First-Generation Students' Information Literacy in Everyday Contexts," Journal of Information Literacy 13, no. 2 (2019): 73-91.

34. Irving Seidman, Interviewing as Qualitative Research: A Guide for Researchers in Education and the Social Sciences, 4th ed. (New York, NY: Teachers College Press, 2009).

35. Seidman, Interviewing as Qualitative Research, 21.

36. Max van Manen, Phenomenology of Practice: Meaning-Giving Methods in Phenomenological Research and Writing (Walnut Creek, CA: Left Coast Press, 2014).

37. Van Manen, Phenomenology of Practice.

38. Folk, "Drawing on Students' Funds of Knowledge"; Folk, "Learning the Rules of Engagement."

39. Folk, "Drawing on Students' Funds of Knowledge"; Folk, "Learning the Rules of Engagement."

40. Susan A. Ambrose et al., How Learning Works: Seven Research-Based Principles for Smart Teaching (San Francisco, CA: Jossey-Bass, 2010).

41. Michele Eodice, Anne Ellen Geller, and Neal Lerner. The Meaningful Writing Project: Learning, Teaching, and Writing in Higher Education (Logan, UT: Utah State University Press, 2016).

42. In a study conducted by Melissa Gross and Don Latham, undergraduate students did not necessarily perceive information literacy or research skills as something to be developed over time. They seemed to believe that anyone can perform these kinds of tasks, especially younger persons whom they perceived as being more familiar with technology. See Melissa Gross and Don Latham, "Undergraduate Perceptions of Information Literacy: Defining, Attaining, and Self-Assessing Skills," College \& Research Libraries 70, no. 4 (2009): 336-50.

43. Michelle Holschuh Simmons, "Librarians as Disciplinary Discourse Mediators: Using Genre Theory to Move Toward Critical Information Literacy," portal: Libraries and the Academy 5, no. 3 (2005): 297-311.

44. Simmons, "Librarians as Disciplinary Discourse Mediators," 298.

45. Folk, "Reframing Information Literacy as Academic Cultural Capital."

46. Jane Hammons provides a nice overview of instructor development programming-sometimes referred to as train-the-trainer or teach-the-teacher programming-in Jane Hammons, "Teaching the Teachers to Teach Information Literacy: A Literature Review," Journal of Academic Librarianship 46, no. 5 (2020): 1-13. The following citations provide a few recent examples of instructor development programming: Jane Hammons et al., "Beyond the Library Walls: How a Faculty Institute Transformed Information Literacy Education across Campus," Kentucky Libraries 83, no. 1 (2019): 7-11; Hicks and Howkins, "Tipping the Iceberg"; Barbara Junisbai, M. Sara Lowe, and Natalie Tagge, "A Pragmatic and Flexible Approach to Information Literacy: Findings from a Three-Year Study of Faculty-Librarian Collaboration," Journal of Academic Librarianship 42, no. 5 (2016), 604-11; Clarence Maybee, IMPACT Learning: Librarians at the Forefront of Change in Higher Education (Oxford, UK: Chandos Publishing, 2018); Rachel Wishkoski, Kacy Lundstrom, and Erin Davis, "Faculty Teaching and Librarian-Facilitated Assignment Design," portal: Libraries and the Academy 19, no. 1 (2019): 95-126; Rachel Wishkoski, Kacy Lundstrom, and Erin Davis, "Librarians in the Lead: A Case for Interdisciplinary Faculty Collaboration on Assignment Design," Communications in Information Literacy 12, no. 2 (2018): 166-92.

47. For recent scholarship on the meaningful contributions that librarians have to make to student learning that is related to the concept of discourse mediator, I recommend Michelle Reale, Inquiry and Research: A Relational Approach in the Classroom (Chicago, IL: American Library Association, 2019).

48. Folk, "Reframing Information Literacy as Academic Cultural Capital."

49. Joan Middendorf and David Pace, "Decoding the Disciplines: A Model for Helping Students to Learn Disciplinary Ways of Thinking," New Directions for Higher Education, no. 98 (summer 2004): 1-12; Joan Middendorf and David Pace, "Decoding the Disciplines: Improving Student Learning," http://decodingthedisciplines.org/ [accessed 28 August 2020].

50. Mary-Ann Winkelmes et al., "A Teaching Intervention that Increases Underserved College Students' Success," Peer Review 18, no. 1/2 (2016), https://www.aacu.org/peerreview/2016/winter-spring/Winkelmes; Office 
of the Executive Vice President and Provost, University of Nevada, Las Vegas, "Transparency in Learning and Teaching in Higher Education," https://tilthighered.com/ [accessed 28 August 2020].

51. See the following for recent scholarship on this topic: Chelsea Heinbach et al., "Dismantling Deficit Thinking: A Strengths-Based Inquiry into the Experiences of Transfer Students in and out of Academic Libraries," In the Library with the Lead Pipe (February 6, 2019), www.inthelibrarywiththeleadpipe.org/2019/dismantling-deficitthinking/ [accessed 28 August 2020]; Tatiana Pashkova-Balkenhol et al., "Should We Flip the Script: A Literature Review of Deficit-Based Perspectives on First-Year Undergraduate Students' Information Literacy," Journal of Information Literacy 13, no. 2 (2019): 92-111. 